\title{
Selective killing of cancer cells harboring mutant RAS by concomitant inhibition of NADPH oxidase and glutathione biosynthesis
}

Muyun Liu' ${ }^{1,2}$, Dan Wang ${ }^{1,3}$, Yongde Luo ${ }^{3,4}$, Lianghao $\mathrm{Hu}^{1}$, Yawei $\mathrm{Bi}^{3}$, Juntao $\mathrm{Ji}^{3}$, Haojie Huang ${ }^{1}$, Guoqiang Wang ${ }^{3}$, Liang Zhu ${ }^{3}$, Jianjia $\mathrm{Ma}^{3}$, Eunice Kim ${ }^{3}$, Catherine K. Luo ${ }^{3}$, James L. Abbruzzese ${ }^{5}$, Xiaokun Li ${ }^{4}$, Vincent W. Yang ${ }^{3}$, Zhaoshen $\mathrm{Li}^{1}$ and Weiqin Lu ${ }^{3}$

\begin{abstract}
Oncogenic RAS is a critical driver for the initiation and progression of several types of cancers. However, effective therapeutic strategies by targeting RAS, in particular RAS ${ }^{G 12 D}$ and RAS ${ }^{G 12 V}$, and associated downstream pathways have been so far unsuccessful. Treatment of oncogenic RAS-ravaged cancer patients remains a currently unmet clinical need. Consistent with a major role in cancer metabolism, oncogenic RAS activation elevates both reactive oxygen species (ROS)-generating NADPH oxidase (NOX) activity and ROS-scavenging glutathione biosynthesis. At a certain threshold, the heightened oxidative stress and antioxidant capability achieve a higher level of redox balance, on which cancer cells depend to gain a selective advantage on survival and proliferation. However, this prominent metabolic feature may irrevocably render cancer cells vulnerable to concurrent inhibition of both NOX activity and glutathione biosynthesis, which may be exploited as a novel therapeutic strategy. In this report, we test this hypothesis by treating the HRAS ${ }^{G 12 V}$-transformed ovarian epithelial cells, mutant KRAS-harboring pancreatic and colon cancer cells of mouse and human origins, as well as cancer xenografts, with diphenyleneiodonium (DPI) and buthionine sulfoximine (BSO) combination, which inhibit NOX activity and glutathione biosynthesis, respectively. Our results demonstrate that concomitant targeting of NOX and glutathione biosynthesis induces a highly potent lethality to cancer cells harboring oncogenic RAS. Therefore, our studies provide a novel strategy against RAS-bearing cancers that warrants further mechanistic and translational investigation.
\end{abstract}

\section{Introduction}

Abnormal activation of RAS signaling pathways by the acquisition of oncogenic mutations in KRAS, HRAS, or NRAS is frequently observed in human cancers ${ }^{1-4}$. Given the difficulty in developing a clinically effective RAS inhibitor as well as the complexity of RAS downstream pathways, a growing number of studies have been focusing on metabolic vulnerabilities conferred by

\footnotetext{
Correspondence: Zhaoshen Li (zhaoshenli@hotmail.com) or Weiqin Lu (weiqin.lu@stonybrookmedicine.edu)

'Department of Gastroenterology, Changhai Hospital, Shanghai, China 2Department of Gastroenterology, No. 905 Hospital, Shanghai, China Full list of author information is available at the end of the article These authors contributed equally: Muyun Liu, Dan Wang, Yongde Luo Edited by B. Zhivotovsky
}

oncogenic RAS $^{5-9}$. Previous studies have shown that oncogenic RAS activation significantly augmented the activities of NOXs, which increase cellular ROS levels, leading to redox dysregulation and aberrant metabolic alterations ${ }^{10-13}$. NOXs are a group of seven membranebound multi-component enzymes, namely NOX1, NOX2 (gp91phox), NOX3, NOX4, NOX5, DUOX1, and DUOX2, capable of oxidizing NADPH to NADP ${ }^{+}$, leading to the generation of superoxide by one-electron reduction of oxygen ${ }^{14}$. The bioactive complexes of NOXs, e.g., NOX1 to NOX3, comprise the homologous cytosolic subunits, such as NOX organizer subunits (NOXO1 and p47phox), NOX activator subunits (NOXA1 and NOXA2/p67phox), and a Rho GTPase (Rac1 or Rac2),

\section{(c) The Author(s) 2021}

(c) (i) Open Access This article is licensed under a Creative Commons Attribution 4.0 International License, which permits use, sharing, adaptation, distribution and reproduction cc) in any medium or format, as long as you give appropriate credit to the original author(s) and the source, provide a link to the Creative Commons license, and indicate if changes were made. The images or other third party material in this article are included in the article's Creative Commons license, unless indicated otherwise in a credit line to the material. If material is not included in the article's Creative Commons license and your intended use is not permitted by statutory regulation or exceeds the permitted use, you will need to obtain permission directly from the copyright holder. To view a copy of this license, visit http://creativecommons.org/licenses/by/4.0/. 
and the membrane-associated catalytic core of NOX, including one of several NOX isoforms and the docking subunit p22phox, the latter of which is encoded by CYBA gene $^{14,15}$. The catalytic subunits of NOXs have six or seven transmembrane domains with two heme-binding regions and a NADPH binding region to facilitate superoxide production ${ }^{15}$. The NOX-generated superoxide can be converted to other forms of ROS or detoxified by reduced glutathione and glutathionecoupled antioxidant enzymes, such as glutathione peroxidases (GPXs) and glutathione reductase (GR), to maintain redox homeostasis. Mounting evidence supports the notion that oxidative stress is a common feature of human cancers ${ }^{16-18}$.

In addition to the abnormally elevated NOX activity that accentuates oxidative stress, a marked elevation in antioxidant levels is another unique metabolic feature of oncogenic RAS activation ${ }^{19}$. Glutathione, a cellular thiol serving as a major determinant of cellular redox equilibrium, was found to be enriched through increased biosynthesis in cells with oncogenic KRAS ${ }^{19}$. This finding is consistent with studies showing that the activation of oncogenic RAS increased the total cellular glutathione pool $^{12,20,21}$. Furthermore, stabilization of NRF2 in cancer cells harboring oncogenic RAS induces genes encoding stress-responsive enzymes, including GPXs, $\mathrm{NAD}(\mathrm{P}) \mathrm{H}$ : quinone oxidoreductase-1 (NQO1), glutamate-cysteine ligase (GCL), GR, heme oxygenase-1 (HO-1), and glutathione S-transferase (GST), some of which are directly involved in cellular glutathione biosynthesis and ROS detoxification $^{22-24}$. Elevated antioxidant capacity underlies an important mechanism by which the oncogenic RAStransformed cells adapt to adverse oxidative stress conditions while fueling rapid growth and proliferation ${ }^{25,26}$.

Cancer cells expressing oncogenic RAS appear to exhibit both an enhanced NOX activity, which increases ROS levels, and an increased cellular glutathione pool, which counteracts oxidative stress. We propose that these seemingly contrary events result in a higher level of redox balance, which serves to facilitate malignant transformation; on the other hand, this prominent metabolic feature would render cancer cells highly vulnerable to simultaneous inhibition of both pathways. Based on this hypothesis and our previous work ${ }^{10}$, we tested in this study the combinatory killing effects of $\mathrm{BSO}$, a potent specific inhibitor of GCL in glutathione biosynthesis ${ }^{27}$, and DPI, a widely used NOX inhibitor ${ }^{28}$, on $H R A S^{G 12 V}$-transformed ovarian epithelial cells, mutant KRAS-bearing pancreatic and colon cancer cells, and murine pancreatic cancer cells harboring both KRAS and p53 mutations. We observed a considerably elevated sensitivity of these diverse types of cancer cells to the combined BSO and DPI treatment in vitro, as well as a high efficacy of this treatment regime on suppressing the growth of cancer xenografts in athymic nude mice in vivo. Our study demonstrates that the combined DPI and BSO treatment exerts a high lethality to cancer cells harboring intractable RAS oncogenes and may hold great potential for clinical application.

\section{Materials and methods}

\section{Genetically engineered mouse strains}

Kras $^{\text {LSL-G12D/+ }}$ mice $^{29}$ and fElas ${ }^{\text {CreERT }}$ mice ${ }^{30,31}$ were crossed to generate fElas ${ }^{\text {CreERT }}$;Kras ${ }^{\text {LSL-G12D/+ }}$ doubletransgenic mice (called Kras ${ }^{G 12 D /+}$ mice after Tamoxifen induction). fElas ${ }^{\text {CreERT }}$;rp $53^{\text {LSL-R172H/+ }}$ mice $^{31}$ were crossed with $f$ Elas ${ }^{\text {CreERT }}$;Kras ${ }^{\text {LLL-G12D/+ }}$ mice to generate fElas $^{\text {CreERT }}$;Kras ${ }^{\text {LSL-G12D/+ }}$; Trp $53^{\text {LSL-R172H/+ }}$ mice (called KPC mice after Tamoxifen induction). At 60 days of age, male and female fElas ${ }^{C r E R T}, K R A S^{G 12 D /+}$, and KPC mice were randomly recruited and treated with tamoxifen (TM). Three weeks post TM induction, the pancreata were collected for experiments. All these animal experiments were reviewed and approved by the Stony Brook University Institutional Animal Care and Use Committee (IACUC).

\section{Cell lines and reagents}

The immortalized non-tumorigenic normal ovarian epithelial T72 cell line and the tumorigenic $H R A S^{G 12 V}$. transformed T72Ras cell line were generated as previously described $^{12,32}$. Both T72 and T72Ras cells were cultured in a 1:1 mixture of M199 and MCDB105 (Sigma-Aldrich) with $10 \mathrm{ng} / \mathrm{ml}$ epidermal growth factor and $15 \%$ fetal bovine serum. Panc-1 cells were human patient-derived pancreatic ductal adenocarcinoma (PDAC) cancer cell line (from ATCC) that carries both oncogenic KRAS and $p 53$ mutations $^{33}$. Murine KPC cells were generated from PDAC tumors of KPC mice carrying both KRAS ${ }^{G 12 D}$ and $p 53^{R 172 H}$ mutations $^{34}$. L3.6pl cells, which were generated from metastatic liver nodules of a pancreatic cancer patient $^{35}$ carrying the KRAS ${ }^{G 12 D}$ mutation $^{36}$, were generously provided by Dr. Isaiah J. Fidler (The University of Texas MD Anderson Cancer Center, Houston, TX). Panc1, L3.6pl, and KPC cells were cultured in DMEM (Gibco) supplemented with $10 \%$ fetal bovine serum (FBS), penicillin, and streptomycin (Invitrogen). HCT116 $\mathrm{p}^{+/+}$ colon cancer cells (called HCT116 $6^{+/+}$) carrying wild-type p53 and their isogenic HCT116 p53 ${ }^{-1-}$ cells (called HCT $116^{-1-}$ ) were cultured in McCoy5 (Hyclone) medium with $10 \%$ FBS. All the cells were free of mycoplasma contamination. DPI, BSO, N-acetyl-L-cysteine (NAC), and propidium iodide (PI) were purchased from Sigma, and Annexin V was from BD Biosciences. The different ranges of the effective concentrations of DPI and BSO for different cell lines or xenografts were pre-determined in pilot experiments or followed our previous studies. 


\section{Assays for cellular total glutathione (GSX)}

Cellular glutathione was measured using a glutathione assay kit (Beyotime Institute of Biotechnology, Shanghai, China) according to the manufacturer's instruction. Briefly, L3.6pl, Panc-1, or KPC cells were treated with different concentrations of BSO in a six-well plate for 24 or $72 \mathrm{~h}$. After treatment, cells were harvested and homogenized, and the cell content was deproteinized. Total cellular glutathione levels were determined by measuring the product of glutathionylated DTNB by a UV spectrophotometer at $412 \mathrm{~nm}$. A standard curve was generated for calculating cellular glutathione levels.

\section{Determination of cell death}

Cell death was determined by flow cytometry after cells were double-stained with annexin-V and PI (BD PharMingen, San Diego, CA). Briefly, after drug treatment, cells were harvested and washed twice with cold PBS and then stained with annexin- $\mathrm{V}$ for $15 \mathrm{~min}$ at room temperature in the dark, followed by staining with PI. The levels of cell death were then determined by measuring the fluorescence intensity of the cells using a BD FACSCalibur flow cytometer equipped with CellQuest Pro software. Ten thousand cells were analyzed per sample.

\section{Colony formation assay}

HCT $116^{+/+}$and HCT $116^{-/-}$cells were seeded in sixwell plates. Culture media were replaced with $3 \mathrm{ml}$ of fresh media containing BSO and/or DPI at the specified experimental concentrations, and cells were incubated for 14 days. Survival colonies were stained with $0.2 \%$ crystal violet (Sigma).

\section{Gene expression analysis}

The expression levels of glutamate-cysteine ligase catalytic subunit $(G C L C)$, glutamate-cysteine ligase regulatory subunit $(G C L M)$, glutathione synthetase (GSS), GR, GPX1, and GPX4 genes relative to $\beta$-actin were analyzed by qRT-PCR as described ${ }^{10}$. Total RNA isolation, 1st strand cDNA synthesis, quantitative PCR were performed as described. Briefly, cell pellets or tissues were homogenized in $1 \mathrm{ml}$ TRIzol Reagent (Ambion, Life Technologies, CA), total RNAs were separated from other cell contents by sequential chloroform and isopropanol precipitation. Aliquots of RNA samples were quantified and examined before reverse transcription using a Nanodrop spectrophotometer. The primer sets used for gene expression analysis by qRT-PCR include $C Y B A$, forward 5'-GATCGAGTGGGCCATGT-3' and reverse $5^{\prime}$ TGCTTGATGGTGCCTCC; GCLC, forward 5'-GGCAC AAGGACGTTCTCAAGT- ${ }^{\prime}$ and reverse $5^{\prime}$-CAAAGGG TAGGATGGTTTGGG-3'; GCLM, forward 5'-TGTGTG ATGCCACCAGATTTG- $3^{\prime}$ and reverse $5^{\prime}$-CGTGCGCT TGAATGTCAGG-3'; GSS, forward 5'-CTCTACGGCT
CACCCAATGC-3' and reverse 5'-TCGTCGGATCACA TGGATGTT-3'; GSR (GR), forward 5'-AGTGATCCCA AGCCCACAATA and reverse 5'-CACCAATGTAACC TGCACCAA; GPX1, forward 5'-CTCTTCGAGAAGTGC GAGGT-3' and reverse 5'-GATGTCAGGCTCGATGT CAA- $3^{\prime}$; and GPX4, forward 5'-AGTGAGGCAAGACCG AAGTAA- $3^{\prime}$ and reverse $5^{\prime}$-TCCTGCTTCCCGAACTG GT-3'. Gene expression levels were determined by qRTPCR in the Quantifast SYBR Green PCR mix (Qiagen $\mathrm{GmbH}$, Germany) with a reaction condition of initial denaturation at $95^{\circ} \mathrm{C}$ for $5 \mathrm{~min}$ and then 40 cycles of $95^{\circ} \mathrm{C}$ for $10 \mathrm{~s}$ and $60^{\circ} \mathrm{C}$ for $30 \mathrm{~s}$ in QuantStudio 3 machine. The comparative threshold $\mathrm{Ct}$ method was used with $\beta$-actin as an internal reference. Data quantification and statistical analysis were performed in Microsoft Excel and GraphPad Prism 6.0.

\section{Protein isolation and Western blot analysis}

To evaluate protein levels, cell lysates were separated by SDS-PAGE and analyzed by Western blot as described ${ }^{10}$. Briefly, cell pellets or snap-frozen tissues were homogenized in a lysis buffer containing $10 \mathrm{mM}$ Tris- $\mathrm{HCl}, \mathrm{pH}$ 6.8-7.5, 2 mM EDTA, 0.5\% SDS, and freshly added 2mercaptoethanol. Tissue homogenates were centrifuged at $12,000 \mathrm{~g}$ for $15 \mathrm{~min}$ at $4{ }^{\circ} \mathrm{C}$, and the supernatants were collected. The total protein extracts were aliquoted to determine protein concentration using a protein assay dye reagent concentrate (Bio-Rad, CA, USA). About $100 \mu \mathrm{g}$ total protein was separated by SDS-PAGE and then transferred to nitrocellulose membrane. The membranes were probed with the following antibodies against p22phox (1:500; sc-20781, Santa Cruz), GCLC (1:600; sc28965, Santa Cruz), GR (1:500; sc-13324, Santa Cruz), and $\beta$-actin (1:10000, Sigma-Aldrich), washed with PBST and then probed with their respective secondary antibodies conjugated to horseradish peroxidase for $1 \mathrm{~h}$ at room temperature. Autoradiography or the Odyssey Imaging System (LiCor Biosciences, Lincoln, NE) was used to visualize protein bands. Stripping buffer (Thermo, MA, USA) was used for sequential blotting and probing with other antibodies. ImageJ densitometry software was used to quantify individual bands.

\section{Xenograft mouse model}

Isolated murine KPC cancer cells were cultured in DMEM medium containing $10 \%$ FBS to $90 \%$ confluence and collected in $1 \times$ PBS. A total of 32 athymic nude mice at the age of 9 weeks were each injected with $5 \times 10^{5} \mathrm{KPC}$ cells subcutaneously. These mice were randomly divided into four groups. Nine days after injection, the mice were treated with PBS (control), BSO $(500 \mathrm{mg} / \mathrm{kg} /$ day), DPI $(6 \mathrm{mg} / \mathrm{kg} /$ day), or a mixed solution of $500 \mathrm{mg} / \mathrm{kg}$ BSO and $6 \mathrm{mg} / \mathrm{kg}$ DPI per day. Bodyweight and tumor size were measured after the day of KPC cell injection. All mice 
were sacrificed at day 24 (empirically determined) when an unbearable tumor burden (defined as a nodule of $18 \mathrm{~mm}$ diameter at any dimension) emerged in these mice. Tumor size was calculated based on the following equation: tumor volume $\left(\mathrm{mm}^{3}\right)=L \times W \times[(L+W) / 2] \times$ 0.526 , where $L$ is the length and $W$ the width ${ }^{10}$. The experimental treatment schemes for the mice were kept blind to the researchers when the mouse body and tumor parameters were analyzed. KPC cell xenograft mouse models were approved by the IACUC at Changhai Hospital.

\section{Statistics}

In flow cytometry analysis, the Kolmogorov-Smirnov test (Cell Quest Pro software, Becton-Dickinson, San Jose, CA) was used for statistical evaluation among groups. All other statistical analyses were carried out using the Student's unpaired $t$ test (Prism GraphPad, San Diego, CA). The comparison of mouse body weight and tumor growth was carried out using two-way ANOVA. A $p$-value of $<0.05$ is considered to be statistically significant.

\section{Results}

Oncogenic HRAS ${ }^{\mathrm{G} 12 \mathrm{~V}}$-transformed ovarian epithelial cells are vulnerable to the combined BSO and DPI treatment

Our previous studies showed that oncogenic HRAS ${ }^{\mathrm{G} 12 \mathrm{~V}}$ transformation of T72Ras cells led to increases in the expression of genes encoding NOX components, NOX activity, and ROS compared to their parental ovarian epithelial T72 cells ${ }^{10,12}$. Studies also showed a compensatory increase in cellular glutathione in T72Ras cells that exhibit malignant behavior for generating xenograft tumors as compared to T72 cells ${ }^{10,12,32}$. To determine the antioxidant capacity of T72Ras cells, we analyzed the expression of GCLC, GCLM, and GSS in the glutathione synthesis pathway, as well as glutathione-associated $\mathrm{H}_{2} \mathrm{O}_{2}$ detoxification genes, including GR, GPX1, and GPX4. Among these genes, the expression levels of GCLC, GCLM, and GSS were significantly upregulated in T72Ras cells compared to those in T72 cells (Fig. 1a-c), which is in line with previous findings that T72Ras cells have a higher level of cellular glutathione than T72 cells ${ }^{12}$. Western blot analysis revealed that the levels of p22phox were prominent in T72Ras cells (Fig. 1d-f). Although no significant alterations were observed in GR protein levels, GCLC protein level increased significantly in T72Ras cells compared to that in T72 cells (Fig. 1d-f). These data suggest a simultaneous elevation in both the ROSgenerating NOX and the ROS-scavenging glutathione biosynthesis upon the transformation of T72 cells by oncogenic HRAS ${ }^{\mathrm{G} 12 \mathrm{~V}}$.

To determine whether these metabolic alterations create vulnerability in cancer cells to the concurrent inhibition of the elevated NOX activity and glutathione biosynthesis, we first evaluated the cytotoxic effects of inhibiting glutathione biosynthesis comparatively on these isogenic cell lines. As illustrated in Fig. 1g, reduction of total cellular glutathione by BSO treatment alone at 10 , 30 , or $100 \mu \mathrm{M}$ for $30 \mathrm{~h}$ in T72 cells induced cell death ranging from 21.00 to $28.00 \%$ as probed by annexin-V/PI in flow cytometric analysis. In contrast, T72Ras cells were more sensitive to $\mathrm{BSO}$ treatment than T72 cells, with significantly increased cell death ranging from 36.30 to $65.50 \%$, indicating an increased sensitivity of T72Ras cells to the inhibition of glutathione biosynthesis. We then evaluated the cytotoxic effects of NOX inhibitor DPI. T72 cells exhibited a basal level of sensitivity to DPI at 1 and $3 \mu \mathrm{M}$ with cell death ranging from 4.30 to $5.70 \%$, while T72Ras cells had a little increase in cell death ranging from 7.50 to $12.70 \%$ after being treated for $30 \mathrm{~h}$ (Fig. $1 \mathrm{~h}$ ). In marked contrast, a combined treatment with $1 \mu \mathrm{M}$ DPI and $10 \mu \mathrm{M}$ BSO significantly enhanced cytotoxicity to T72Ras cells with $70.00 \%$ cell death vs. $11.60 \%$ in T72 cells (Fig. 1i). This combined regimen resulted in approximately a 6-fold increase in the death of T72Ras cells over T72 cells, a more than 9-fold increase over T72Ras cells with $1 \mu \mathrm{M}$ DPI treatment alone, and about a 2-fold increase with $10 \mu \mathrm{M}$ BSO treatment alone (Fig. 1g-i). Increasing BSO concentrations to $30 \mu \mathrm{M}$ and $100 \mu \mathrm{M}$ did not significantly increase the cytotoxic effect on T72Ras cells, which exhibited a rate of cell death ranging from 71.80 to $74.00 \%$, compared to the slightly increased killing effect on T72 cells ranging from 17.40 to $19.70 \%$. Overall, these data suggest that the $H R A S^{G 12 V_{-}}$ transformed cells are highly sensitive and selective to the combinatory therapy of BSO and DPI compared to the non-transformed isogenic cells.

\section{Pancreatic cancer patient-derived L3.6pl cells bearing oncogenic KRAS are vulnerable to BSO and DPI combination therapy}

The selectivity and sensitivity of $H R A S^{G 12 V}$-transformed cells to the combined BSO and DPI treatment motivated us to test if patient-derived cancer cells carrying oncogenic RAS are also sensitive to this therapy. Oncogenic $K R A S^{G 12 D}$-bearing L3.6pl cells are highly aggressive pancreatic cancer cells derived from a patient of PDAC with liver metastasis ${ }^{36}$. As the concentration of BSO used for effective inhibition of cellular glutathione biosynthesis varies with different cell types ${ }^{19,26}$, we first measured cellular total glutathione levels of L3.6pl cells after treatment with BSO at concentrations of $0,50,100$, or $200 \mu \mathrm{M}$ for $72 \mathrm{~h}$. As shown in Fig. 2a, $50 \mu \mathrm{M}$ BSO treatment resulted in a $65.82 \%$ reduction of total cellular glutathione $(p<0.001, n=3)$ compared to the control group, while 100 and $200 \mu \mathrm{M}$ BSO treatments reduced total cellular glutathione by $82.98 \%$ and $82.87 \%$, respectively. Therefore, we chose a BSO concentration of $100 \mu \mathrm{M}$, the lowest 
A

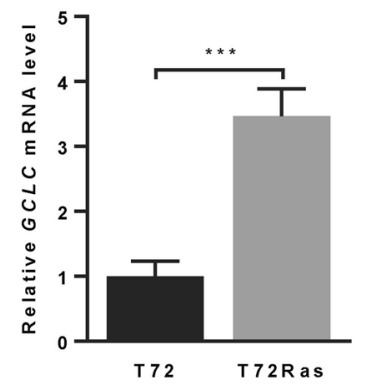

D

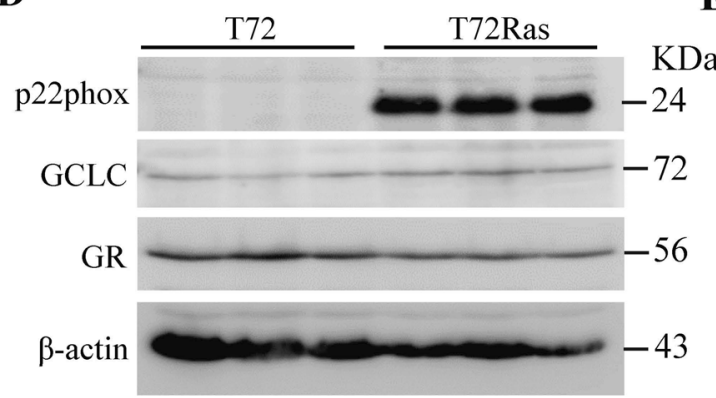

$\mathbf{E}$
C

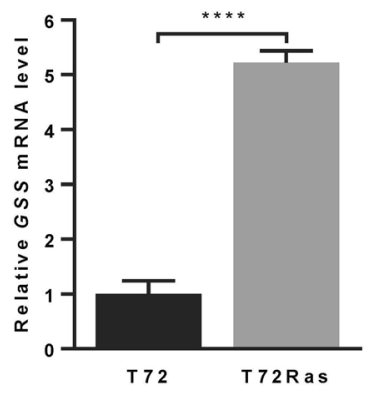

F

G
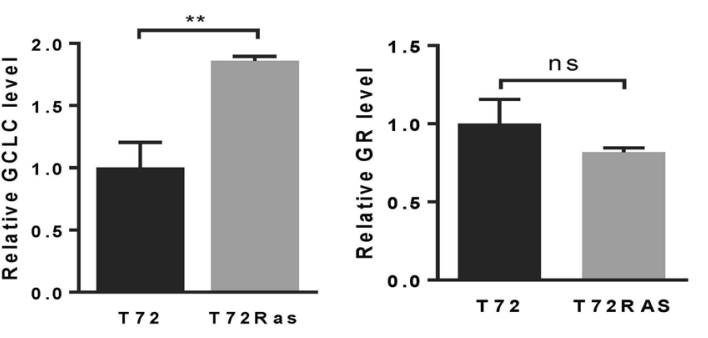

BSO, $\mu \mathrm{M}: \quad 0$

10

$\mathrm{T} 72$
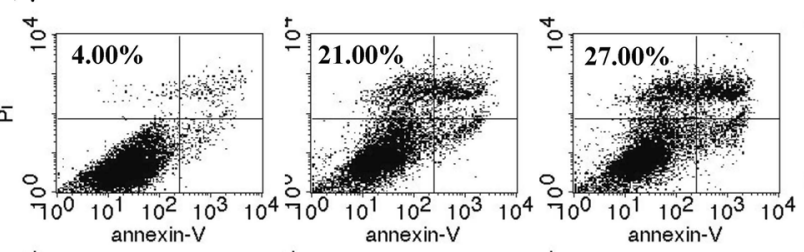

30

100

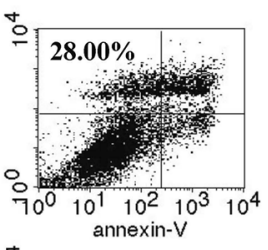

T72Ras ia
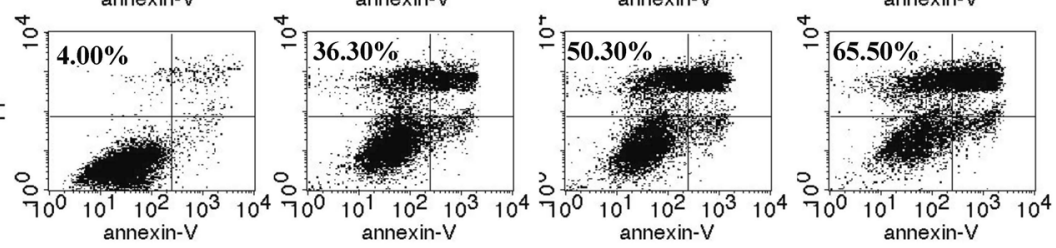

H

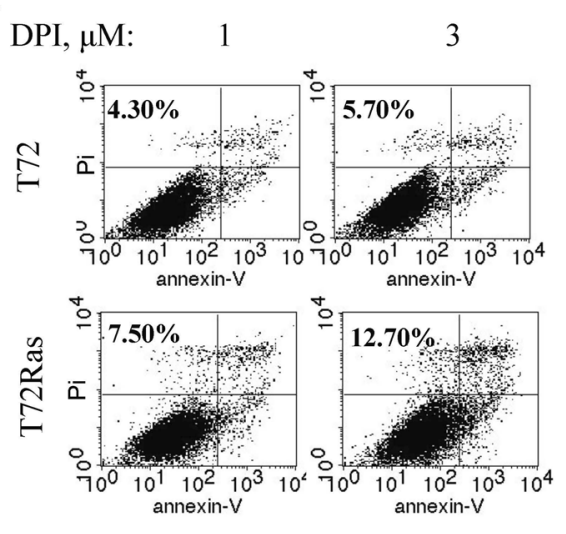

I

BSO, $\mu \mathrm{M}: \quad 10$

DPI, $\mu \mathrm{M}: \quad 1$
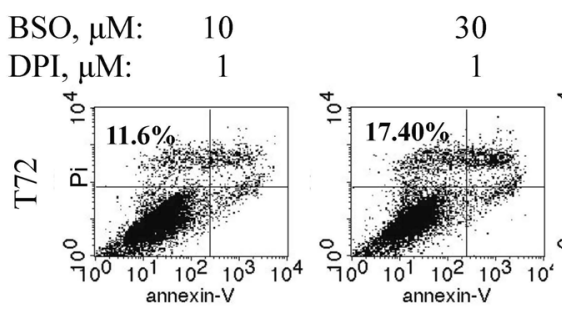

100
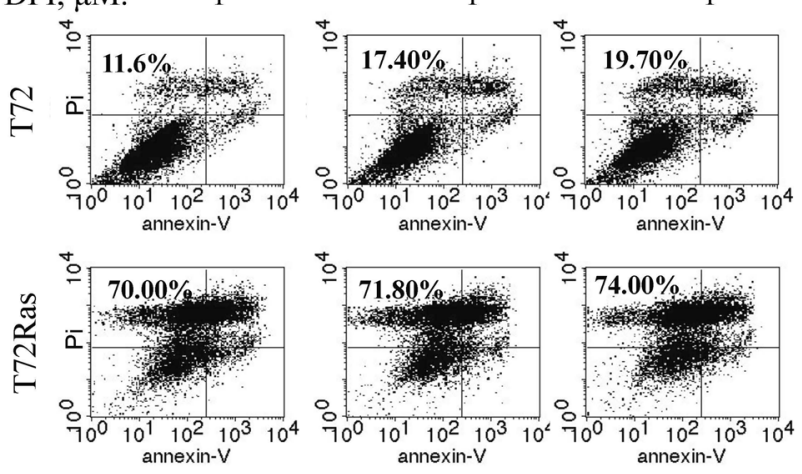

Fig. 1 (See legend on next page.) 
(see figure on previous page)

Fig. 1 Selective cytotoxic effect of BSO and DPI combinatory treatment on oncogenic $H R A S^{G 12 v}$-transformed ovarian epithelial cells. A-C qRT-PCR analysis of the expression levels of GCLC, GCLM, and GSS genes in T72 and T72Ras cells. $\beta$-actin serves as a control. D Western blot analysis of p22phox, GCLC, and GR protein levels in T72 and T72Ras cells. $\beta$-actin serves as a loading control. E-F Quantitative analysis of GCLC and GR protein levels in D. G T72 parental cells and their isogenic HRAS ${ }^{G 12 V}$-transformed T72Ras cancer cells were treated with glutathione biosynthesis inhibitor BSO at $0,10,30$, or $100 \mu \mathrm{M}$ for $30 \mathrm{~h}$. Cell viability was measured by flow cytometry with annexin-V/PI double staining. The numbers shown at the upper left of each panel indicate the percentage of the annexin-V/PI positive cells. H T72 and T72Ras cells were treated with DPI at 1 or $3 \mu \mathrm{M}$ for $30 \mathrm{~h}$. Cell viability was measured as described in $\mathbf{G}$, and cell death was expressed as the percentage of the annexin-V/PI positive cells. I Combined treatment using BSO (10, 30, or $100 \mu \mathrm{M})$ and DPI $(1 \mu \mathrm{M})$ for $30 \mathrm{~h}$ induced significant death of T72Ras cells (lower panel) but not parental T72 cells (upper panel). Data are mean \pm SD of three independent experiments with Student's $t$ test. ${ }^{* *} p<0.01,{ }^{* * *} p<0.001,{ }^{* * *} p<0.0001$. KDa kilodalton.

concentration that induces a maximum glutathione reduction. $100 \mu \mathrm{M}$ BSO treatment alone for $72 \mathrm{~h}$ induced no significant cytotoxicity in L3.6pl cells, while DPI treatment at 1 and $3 \mu \mathrm{M}$ decreased cell viability compared to without any treatment. When combined with $100 \mu \mathrm{M}$ $\mathrm{BSO}$, viable cells drastically decreased in a DPI dosedependent manner (Fig. 2b). Evaluation of cell death with annexin-V/PI staining revealed that 1 and $3 \mu \mathrm{M}$ of DPI treatment for $72 \mathrm{~h}$ led to a dose-dependent increase in cell death at $23.07 \%$ and $34.36 \%$, respectively (Fig. 2c). BSO at $100 \mu \mathrm{M}$ exerted no significant cytotoxicity to L3.6pl cells, even though a reduction of about $83 \%$ in glutathione was observed (Fig. 2a, c). Strikingly, combination treatment with BSO and DPI was effective in inducing L3.6pl cell death, which increased to $57.00 \%$ under $100 \mu \mathrm{M}$ BSO and $1 \mu \mathrm{M}$ DPI and to $87.29 \%$ under $100 \mu \mathrm{M}$ BSO and $3 \mu \mathrm{M}$ DPI for $72 \mathrm{~h}$ (Fig. 2c). These results indicate a cooperative cytotoxic effect of combined treatment on L3.6pl cells.

To evaluate whether this remarkably cooperative killing effect is dependent on a redox-mediated mechanism, we used NAC, an $\mathrm{N}$-acetyl derivative of $\mathrm{L}$-cysteine and a precursor in the formation of glutathione, to replenish the reduced cellular glutathione pool. After incubation with $100 \mu \mathrm{M}$ BSO and $3 \mu \mathrm{M}$ DPI in the presence of $2 \mathrm{mM} \mathrm{NAC}$ for $72 \mathrm{~h}$, the death rate of $\mathrm{L3} .6 \mathrm{pl}$ cells significantly decreased from $88.38 \pm 6.46 \%$ in the absence of NAC to $47.51 \pm 6.57 \%$ in the presence of NAC (Fig. $2 \mathrm{~d}$, e). These results suggest that the cooperative killing effect induced by BSO and DPI combination treatment involves, at least in part, a redox-mediated mechanism, which also reflects the acquired dependence of cancer cells on elevated glutathione.

\section{Colon cancer cells harboring oncogenic KRAS are sensitive to BSO and DPI combined therapy}

p53 mutations significantly promote invasive cancer formation in the presence of RAS mutations, which are often observed in many cancer patients ${ }^{34}$. Our previous studies have shown that KRAS-mutated colon cancer cells with p53 deletion have a higher NOX activity and are sensitive to NOX inhibition compared to cells with wildtype $\mathrm{p} 53^{10}$. Here, by using qRT-PCR analysis on a pair of isogenic colon cancer cell lines, the HCT116 cells harboring mutant KRAS with wild-type p53 (called HCT $116^{+/+}$) or $p 53$ deletion $\left(\mathrm{HCT} 116^{-/-}\right.$), we found that the expression levels of CYBA, GCLC, and GCLM significantly increased in $\mathrm{HCT} 116^{-/-}$cells compared to that in $\mathrm{HCT} 116^{+/+}$cells $^{8,10}$ (Fig. 3a-c).

The simultaneous elevation of both ROS-generating NOX and ROS-scavenging GCL in $\mathrm{HCT}_{116}{ }^{-1-}$ cells inspired us to test the effectiveness of $\mathrm{BSO}$ and DPI combination therapy. Treatment with $100 \mu \mathrm{M}$ BSO or $0.1 \mu \mathrm{M}$ DPI alone for $24 \mathrm{~h}$ did not induce significant cell death in either HCT116 $6^{+/+}$or HCT116 ${ }^{-/-}$cells compared to cells without any treatment (Fig. 3d). While treatment with DPI alone at $1 \mu \mathrm{M}$ for $24 \mathrm{~h}$ only induced death in $11 \%$ of $\mathrm{HCT}_{11} 6^{+/+}$cells and $11.9 \%$ of $\mathrm{HCT} 116^{-1-}$ cells (Fig. 3d), the combination with $100 \mu \mathrm{M}$ BSO induced dramatic cell death in $55.10 \%$ of HCT116 ${ }^{+/+}$cells and $76.30 \%$ of $\mathrm{HCT} 116^{-/-}$cells (Fig. 3e), demonstrating the effectiveness of the combination treatment in killing cancer cells bearing oncogenic KRAS and p53 mutations. Given our previous studies showing that $10 \mu \mathrm{M}$ DPI treatment for $24 \mathrm{~h}$ led to $17 \%$ cell death in HCT116 ${ }^{+/+}$ cells and $32 \%$ in HCT $116^{-1-}$ cells $^{10}$, our data indicate that a 10-fold less concentration of DPI can reach a better efficacy when combined with BSO. Notably, these data also showed that HCT116 ${ }^{-/-}$cells are more sensitive to the combined treatment than HCT116 ${ }^{+/+}$cells (Fig. 3e). Colony formation assay confirmed that the combined treatment of BSO $(100 \mu \mathrm{M})$ and DPI $(>0.1 \mu \mathrm{M})$ substantially inhibited the colony formation ability of both HCT $116^{+/+}$and HCT $116^{-1-}$ cells compared to any single treatment (Fig. 3f-h).

\section{BSO and DPI combined therapy effectively kills pancreatic} cancer cells harboring both KRAS and p53 mutations

We further tested the cytotoxic effect of this combinatory treatment in PDAC cells harboring both KRAS and p53 mutations. Panc-1 cells are derived from a poorly differentiated primary pancreatic cancer patient with both KRAS and $p 53$ mutations $^{33} .100 \mu \mathrm{M}$ BSO or $0.1 \mu \mathrm{M}$ DPI treatment alone had no significant impact on Panc-1 cells, while joint treatment with BSO and DPI for $72 \mathrm{~h}$ effectively induced Panc-1 cell death (Fig. 4a). Since $100 \mu \mathrm{M}$ BSO treatment did not induce any morphological changes 
A

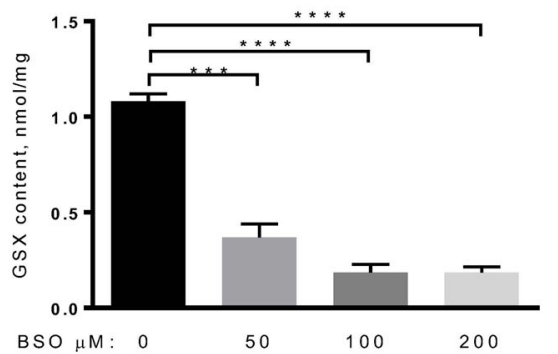

C
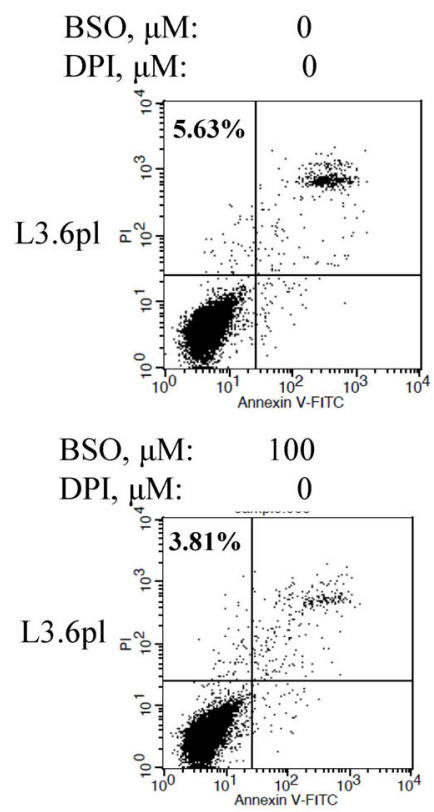

D
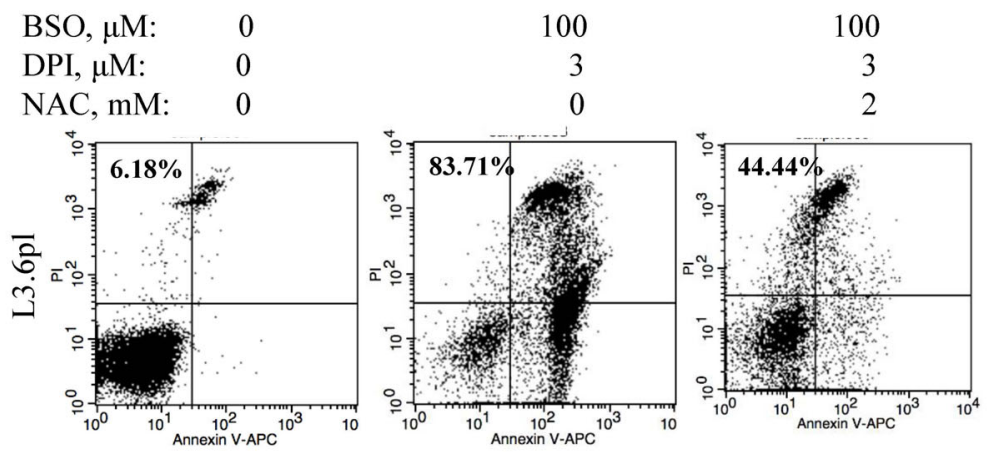

L3.6pl, 72 hrs drug treatment
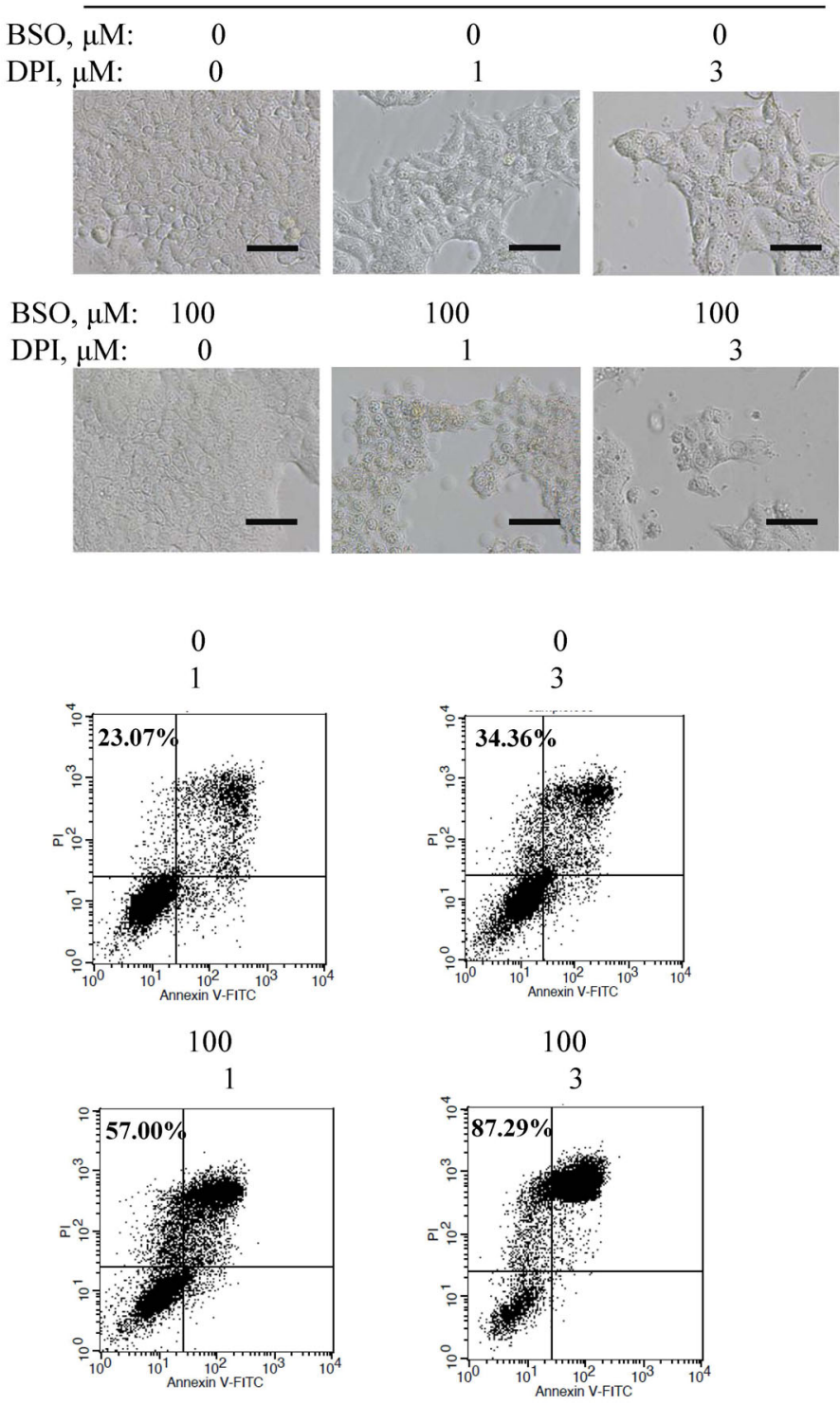

$\mathbf{E}$

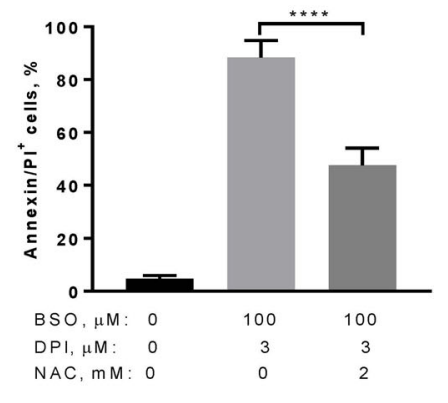

Fig. 2 (See legend on next page.) 
(see figure on previous page)

Fig. 2 Cytotoxicity induced by BSO and DPI combinatory treatment in highly metastatic pancreatic cancer cells. A Total cellular glutathione (GSX), including reduced and oxidized glutathione, was measured after $72 \mathrm{~h}$ of BSO treatment at 0,50, or $100 \mu \mathrm{M}$ in L3.6pl cells by spectrophotometry. B L3.6pl cells were treated with DPI alone (1 or $3 \mu \mathrm{M})$, BSO $(100 \mu \mathrm{M})$ alone, or BSO $(100 \mu \mathrm{M})$ and DPI $(1$ or $3 \mu \mathrm{M})$ for $72 \mathrm{~h}$. Cell morphology and population growth were compared under a light microscope. Scale bar, $200 \mu \mathrm{m}$. C L3.6pl cells were treated as described in B for $72 \mathrm{~h}$. The cell death rate was measured by flow cytometry using annexin-V and PI as probes and expressed as a percentage of the annexin-V/PI positive cells. L3.6pl cells without any treatment served as controls. D L3.6pl cells were treated with a combination of $3 \mu \mathrm{M}$ DPI and $100 \mu \mathrm{M}$ BSO in the presence or absence of $2 \mathrm{mM}$ NAC for $72 \mathrm{~h}$. Cell death rates were determined by Annexin V/PI double staining. E Statistic analysis of cell death rate of $\mathrm{L} 3.6 \mathrm{pl}$ cells treated in $\mathbf{D}$. Data are mean $\pm \mathrm{SD}$ of three independent experiments with Student's $t$ test. ${ }^{* * *} p<0.001,{ }^{* * * *} p<0.0001$.

to Panc-1 cells, we thought that BSO at this concentration might be insufficient in depleting cellular glutathione. However, measurement of total cellular glutathione content revealed that $100 \mu \mathrm{M}$ BSO treatment for $24 \mathrm{~h}$ was sufficient to decrease the content to a nearly undetectable level as compared to the non-treatment control cells (Fig. 4b, $p<0.0001, n=3$ ). Western blot analysis revealed the prominent expression of p22phox in Panc-1 cells, as well as in $\mathrm{KARS}^{\mathrm{G} 12 \mathrm{~V}}$-transfected normal human pancreatic ductal epithelial (HPDE-KRAS ${ }^{\mathrm{G} 12 \mathrm{~V}}$ ) cells, compared to normal HPDE cells (Fig. 4c). Flow cytometry of Panc-1 cells with annexin V/PI staining showed that treatment with DPI alone at 0.1 and $0.3 \mu \mathrm{M}$ for $72 \mathrm{~h}$ induced $11.00 \%$ and $17.00 \%$ of cell death, respectively (Fig. 4d, upper panel), and similarly, BSO treatment alone at $100 \mu \mathrm{M}$ induced $16.00 \%$ of cell death (Fig. 4d, lower panel). In marked contrast, DPI treatment at 0.1 or $0.3 \mu \mathrm{M}$ in combination with $100 \mu \mathrm{M}$ BSO for $72 \mathrm{~h}$ induced $80.00 \%$ and $91.00 \%$ of death of Panc-1 cells, respectively (Fig. 4d, lower panel). These data indicate a high sensitivity of Panc-1 cells to the concomitant reduction in glutathione and NOX activity.

Antioxidant NAC was used to test if the cytotoxicity of the combined BSO and DPI treatment was mediated by a redox-related mechanism. Upon treatment with $2 \mathrm{mM}$ NAC, cell death induced by the combination of $100 \mu \mathrm{M}$ BSO and $0.3 \mu \mathrm{M}$ DPI dropped from $98.34 \pm 0.44 \%$ to $25.79 \pm 12.99 \%$, suggesting that an exogenous antioxidant supplement could largely attenuate the killing effect of the BSO and DPI combination (Fig. 4e, f). Thus, these results suggest that pancreatic cancer cells carrying both $K R A S$ and $p 53$ mutations are vulnerable to BSO and DPI combinatory inhibition, and the cytotoxic effect of BSO and DPI was mainly triggered by a redoxmediated mechanism.

\section{BSO and DPI combined therapy effectively kills pancreatic cancer cells derived from murine KPC tumor}

Studies have shown that mice expressing both $\mathrm{Kras}^{\mathrm{G12D} /+}$ and $p 53^{R 172 H /+}$ at endogenous levels in the pancreata (called KPC mice) rapidly developed PDAC compared to mice expressing Kras ${ }^{G 12 D /+}$ alone ${ }^{29,34,37}$. To determine if the expression of both $\mathrm{Kras}^{\mathrm{G12D/+}}$ and $p 53^{R 172 \mathrm{H} /+}$ results in a higher level of Cyba expression, 60-day-old male and female mice carrying $\mathrm{Kras}^{\mathrm{G12D/} /}, \mathrm{KPC}$, and fElas ${ }^{\mathrm{CreERT}}$ (control) were induced by tamoxifen. Our data revealed that three weeks after tamoxifen induction, pancreatic Cyba mRNA levels of KPC mice were significantly elevated, which were about 3.4 times and 7.4 times higher than that of the Kras ${ }^{G 12 D /+}$ mice and fElas ${ }^{C r e E R T}$ mice, respectively (Fig. 5a).

We then tested the combined killing effects on KPC mice-derived cancer cells. $100 \mu \mathrm{M}$ BSO treatment alone did not cause any detectable change in the growth of KPC cells compared to cells without any treatment (Fig. 5b). Treatment with DPI alone at 3 and $10 \mu \mathrm{M}$ for $48 \mathrm{~h}$ inhibited cell growth (Fig. 5b). However, upon treatment with a combination of $100 \mu \mathrm{M}$ BSO and $10 \mu \mathrm{M}$ DPI, KPC cell growth was further remarkably inhibited (Fig. 5b, lower panel). Glutathione assay revealed that $100 \mu \mathrm{M}$ BSO treatment reduced glutathione levels by $96.90 \%(p<0.01$, $n=3$ ) (Fig. $5 c$ ), even though only minimal cell death was observed (Fig. 5b). Flow cytometric analysis revealed that $100 \mu \mathrm{M}$ BSO and $10 \mu \mathrm{M}$ DPI combination induced cell death in $92.40 \%$ of KPC cells, which is in marked contrast to $8.71 \%$ of cell death by $100 \mu \mathrm{M}$ BSO treatment or $12.55 \%$ of cell death by $10 \mu \mathrm{M}$ DPI treatment (Fig. $5 \mathrm{~d}$ ). NAC treatment at $2 \mathrm{mM}$ partially reversed the cytotoxicity of BSO and DPI combined treatment to KPC cells (Fig. 5e, f).

\section{BSO and DPI combined treatment inhibited pancreatic tumor growth in vivo}

The effectiveness of BSO and DPI combined therapy in killing $R A S$-bearing cancer cells in vitro motivated us to evaluate their tumor-suppressive effects in vivo. Athymic nude mice were inoculated subcutaneously with $5 \times 10^{5} \mathrm{KPC}$ cells, which were shown to be the least sensitive among all the tested cancer cells. The mice were then randomly divided into four groups and treated with PBS, $500 \mathrm{mg} / \mathrm{kg}$ BSO, $6 \mathrm{mg} / \mathrm{kg}$ DPI, or a combination of $500 \mathrm{mg} / \mathrm{kg} \mathrm{BSO}$ and $6 \mathrm{mg} / \mathrm{kg}$ DPI. The body weight of the mice under any treatment regimen did not change significantly (Fig. 6a), suggesting that no noticeable side-effects were induced under these treatment conditions. Tumors in the PBS control group grew rapidly (Fig. 6b, c). Treatment with $500 \mathrm{mg} / \mathrm{kg}$ BSO caused no detectable changes in the size of 


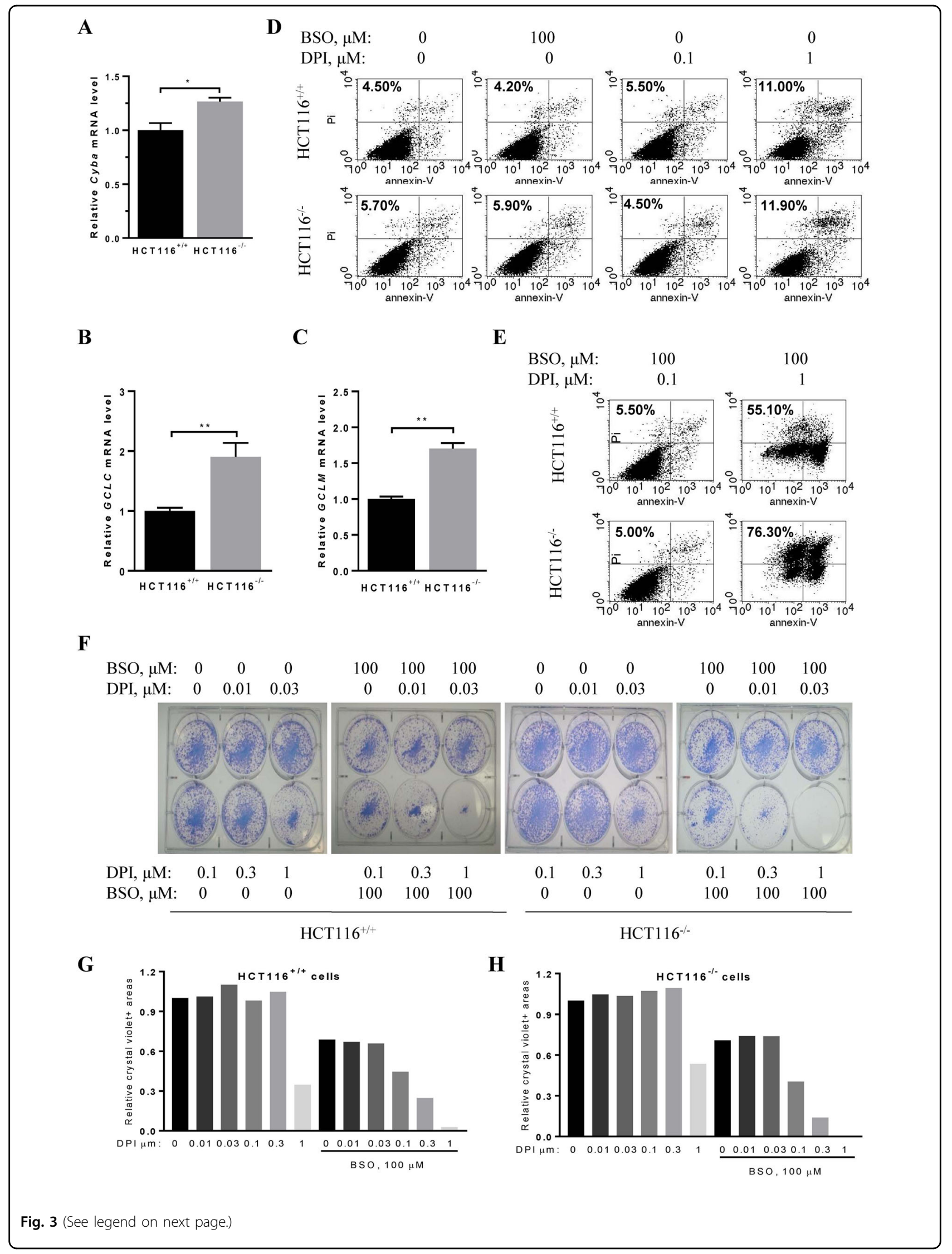


(see figure on previous page)

Fig. 3 BSO and DPI cooperatively induced death of oncogenic KRAS-expressing colon cancer cells with or without p53 mutation. A-C qRTPCR analysis of the expression levels of CYBA (the gene encoding p22phox), GCLC, and GCLM genes in HCT116 $6^{+/+}$and HCT116 $6^{-/-}$cells. $\beta$-actin serves

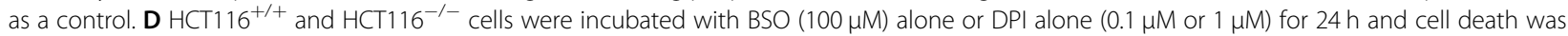
measured by flow cytometry using annexin- $\mathrm{V}$ and PI as probes. E HCT11 $6^{+/+}$and $\mathrm{HCT} 116^{-/-}$cells were incubated with $0.1 \mu \mathrm{M}$ or $1 \mu \mathrm{M}$ DPI in the presence of $100 \mu \mathrm{M}$ BSO for $24 \mathrm{~h}$. The cell death rate was determined with flow cytometry. $\mathbf{F}$ Equal numbers of HCT116 $6^{+/+}$and HCT116 $6^{-/-}$cells were seeded in 6-well plates and treated with DPI at $0,0.01,0.03,0.1,0.3$, or $1 \mu \mathrm{M}$ in the presence or absence of $100 \mu \mathrm{M}$ BSO for 14 days. Cells were stained with crystal violet and photographed. G, H Bar graph presentation of data analysis shown in $\mathbf{F}$. The density of the crystal violet areas in the colonies of either cell line was considered as $1(100 \%)$ for the respective data set. Data are mean \pm SD of three independent experiments with Student's $t$ test. ${ }^{*} p$ $<0.05,{ }^{* *} p<0.01$.

xenograft tumors, and treatment with $6 \mathrm{mg} / \mathrm{kg}$ DPI alone caused a decrease of $18.5 \%$ in tumor size. By contrast, the group with BSO and DPI treatment showed a pronounced restriction on tumor size, with a $53.5 \%$ reduction after 24 days of treatment (Fig. 6b, c). Consistently, simultaneous inhibition of NOX activity and glutathione synthesis caused a notable reduction of $50.6 \%$ in tumor weight compared to no change with BSO treatment or $17.7 \%$ reduction with DPI treatment alone (Fig. 6d). These data indicate that the combined administration of BSO and DPI exerts a significant cooperative effect on deterring tumor growth in mice over any individual treatment regimen.

\section{Discussion}

In this study, we have presented several lines of evidence to support a novel therapeutic strategy against oncogenic $R A S$-expressing cancer cells by concurrently targeting glutathione biosynthesis and NOX activity. We tested this strategy in oncogenic RAS-transformed cells, patient-derived cancer cells, and tumor xenografts in vivo. Our studies reveal that the combined DPI and BSO treatment (1) preferably killed the $H R A S^{G 12 V}$-transformed human ovarian epithelial cells over their normal counterpart; (2) induced massive cell death in the highly metastatic human L3.6pl PDAC cells compared to the individual treatment; (3) exerted a potent and cooperative killing effect on oncogenic KRAS-expressing and p53mutated human colon cancer cells; (4) induced significant cell death of both human and murine PDAC cells harboring KRAS and p53 mutations; (5) suppressed tumor growth of KPC cell xenografts in vivo compared to the individual treatment regimens. Furthermore, the supplement of NAC, a glutathione precursor disrupting the cooperation of BSO and DPI, significantly attenuated the cytotoxic effects of the combination therapy. These results suggest an acquired vulnerability of oncogenic RASbearing cancer cells to the concurrent inhibition of NOX and glutathione biosynthesis. Such a vulnerability caused by oncogenic RAS is in line with evidence showing that cancer cells with oxidative stress are increasingly dependent on the enhanced antioxidant for better survival and aberrant proliferation in adverse metabolic conditions ${ }^{12}$.
Antioxidant signature marked by the elevated glutathione synthesis has been recognized as an important metabolic feature of oncogenic KRAS-mediated malignant transformation ${ }^{19}$. Glutathione pool at an elevated level serves to detoxify the damaging effects of increasing ROS, and therefore, is crucial for the adaptation of cancer cells to oxidative stress for optimal survival and growth ${ }^{16,17}$. Accordingly, inhibition of glutathione biosynthesis has been harnessed as a therapeutic strategy in various preclinical models, including KRAS-driven pancreatic cancer and non-small cell lung cancer ${ }^{19,20,38}$. However, clinical efficacy has always been a limiting issue. Our results have identified DPI as a partner of BSO in exerting profound cytotoxic effects on cancer cells bearing oncogenic $R A S$.

Targeted inhibition of ROS-generating NOX and ROS-scavenging glutathione biosynthesis seems contradictory; however, activation of NOX and enhancement of glutathione biosynthesis have been consistently observed to coexist in $R A S$-mutated cancers ${ }^{10,12}$. These two events cooperate to achieve a higher level of redox balance (Fig. 7a, b) compared to that in the normal cell counterparts, and thus, endow cancer cells with a selective advantage on proliferation with optimal survival over normal cells under adverse conditions ${ }^{16,17}$. Furthermore, the redox system not only involves redoxassociated enzymes, such as the glutathione biosynthesis pathway, GPXs, GR, catalase, superoxide dismutase (SOD), and NOXs, but also intertwines with glucose metabolism, fatty acid oxidation, and mitochondrial function for the generation of reducing equivalent $\mathrm{NADPH}$, with glutamine metabolism for the supplement of glutamate for glutathione synthesis, and with other signaling pathways including NRF2-mediated upregulation of the antioxidant system for a better adaptation to oxidative stress. Thus, the functions of the redox system are multifaceted, which underscore the necessary co-existence of NOX activation and enhancement of glutathione pool acquired as two important survival and proliferation features in cancers. By contrast, normal cells appear to maintain only a basal homeostatic level of antioxidant capacity with minimal oxidative stress, and therefore, are less sensitive to the inhibition of these two redox arms. 
A

Panc-1, 72 hrs drug treatment

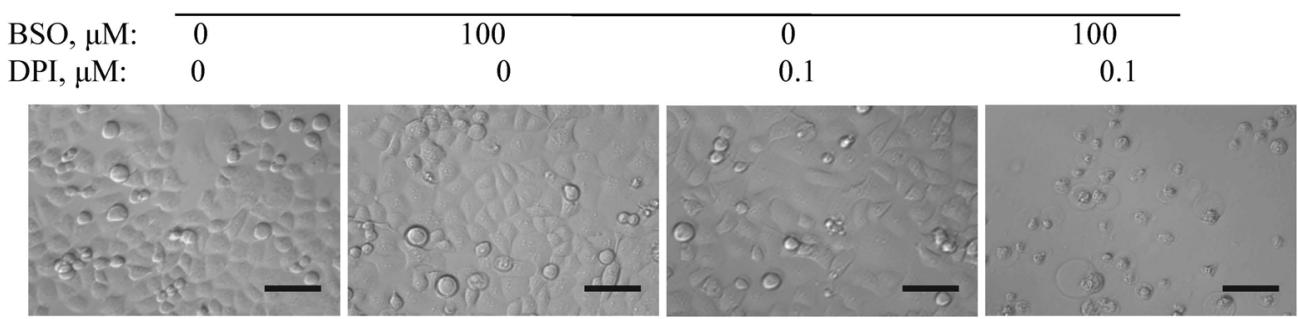

B

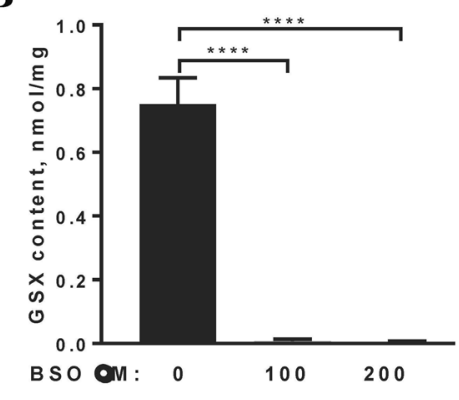

C

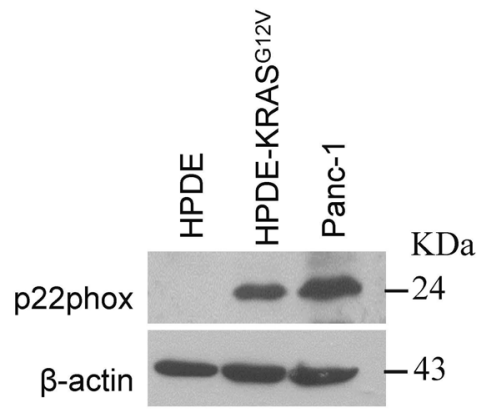

D

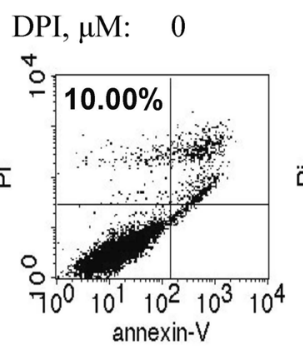

BSO, $\mu \mathrm{M}: 100$

DPI. uM: 0

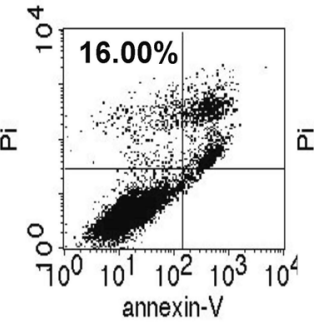

0.1

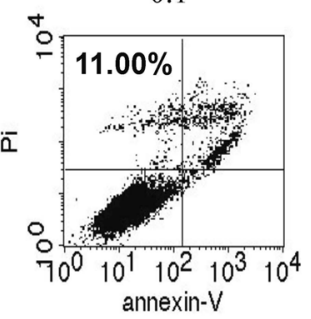

100

0.1

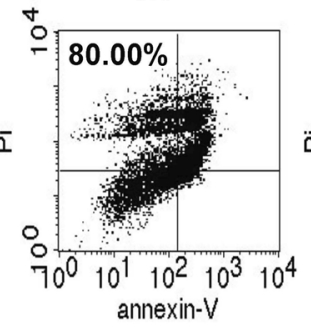

0.3

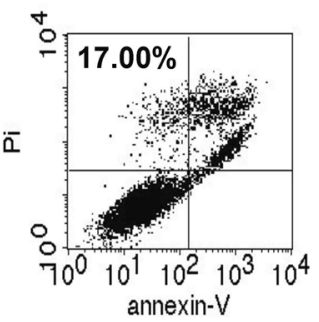

100

0.3

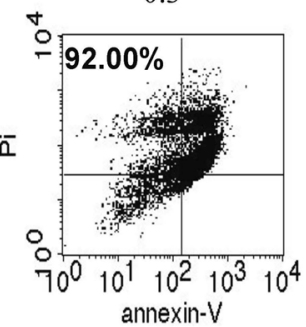

$\mathbf{E}$

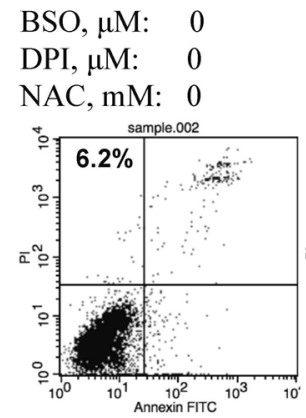

\begin{abstract}
100
\end{abstract}
0.3

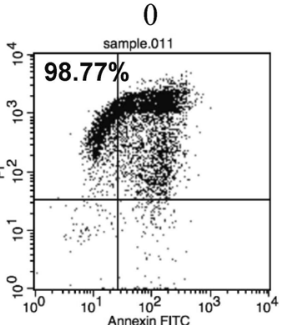

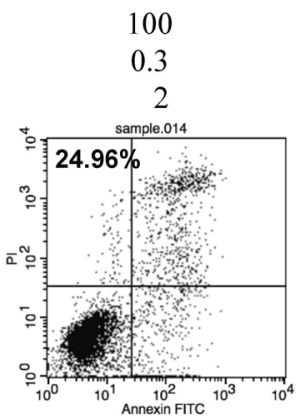

F

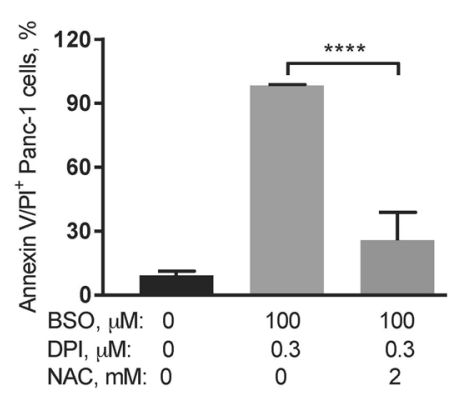

Fig. 4 BSO and DPI cooperatively induce significant death of primary human pancreatic cancer cells. A Comparison of cell morphology and growth in Panc-1 cells after treatment with $0.1 \mu \mathrm{M} \mathrm{DPI}, 100 \mu \mathrm{M}$ BSO, or the combined $100 \mu \mathrm{M} \mathrm{BSO}$ and $0.1 \mu \mathrm{M}$ DPI for $72 \mathrm{~h}$. DPI or BSO treatment alone had a limited impact on Panc-1 cells, while the combined treatment considerably reduced the number of living cells as observed under a light microscope. Scale bar, $200 \mu \mathrm{m}$. B Total cellular glutathione (GSX) levels were measured by spectrophotometry after $24 \mathrm{~h}$ of BSO treatment at 0, 100, or 200 $\mu \mathrm{M}$ in Panc-1 cells. Treatment was performed with three independent experiments. C Western blot analysis of p22phox protein levels in Panc-1 cells and oncogenic KRAS ${ }^{G 12 V}$-transformed HPDE cells as compared to parental HPDE cells. KDa, kilodalton. D Concurrent DPI and BSO treatment induced significant Panc-1 cell death. Cells were incubated with 0.1 or $0.3 \mu \mathrm{M} \mathrm{DPI}, 100 \mu \mathrm{M} \mathrm{BSO}$, or their combination as indicated for $72 \mathrm{~h}$, and cell death was determined by Annexin V/PI double staining. Panc-1 cells without any treatment served as the control. E Panc-1 cells were treated with $0.3 \mu \mathrm{M}$ DPI and $100 \mu \mathrm{M}$ BSO combination in the presence or absence of $2 \mathrm{mM} \mathrm{NAC}$ for $72 \mathrm{~h}$. Cell death rates were determined by Annexin V/PI double staining. F Statistical analysis of the percent death rates of Panc- 1 cells treated in $\mathbf{E}$. Data are mean \pm SD of three independent experiments with Student's $t$ test. ${ }^{* * *} p<0.0001$. 
A

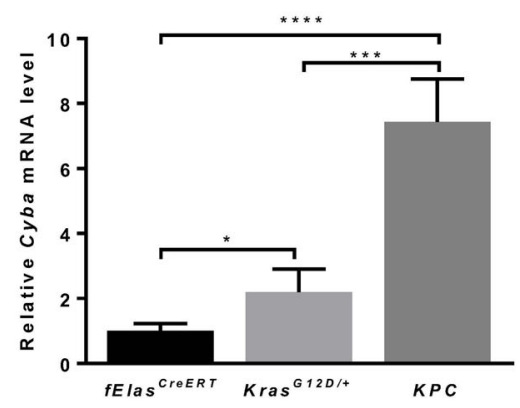

C

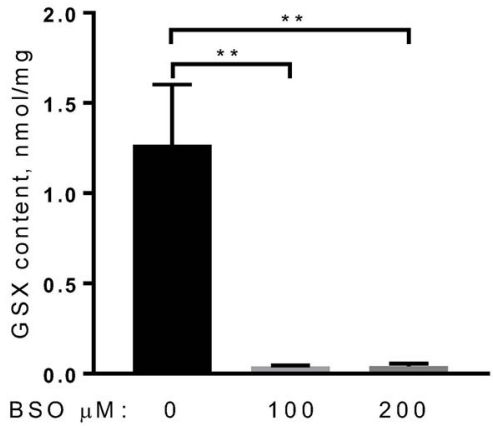

E

$\mathrm{BSO}, \mu \mathrm{M}: \quad 0$

DPI, $\mu \mathrm{M}: \quad 0$

NAC, mM: 0
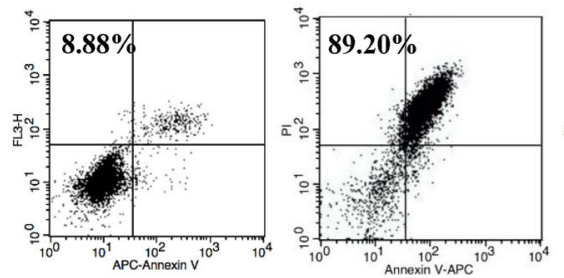

B

D

\begin{tabular}{lccc} 
& \multicolumn{3}{c}{ KPC, 48 hrs drug treatment } \\
\cline { 2 - 4 } BSO, $\mu \mathrm{M}:$ & 0 & 0 & 0 \\
DPI, $\mu \mathrm{M}:$ & 0 & 3 & 10
\end{tabular}
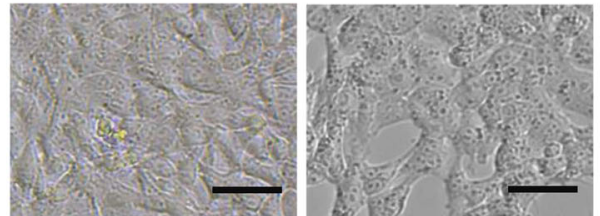

BSO, $\mu \mathrm{M}: 100$

DPI, $\mu \mathrm{M}: \quad 0$

100
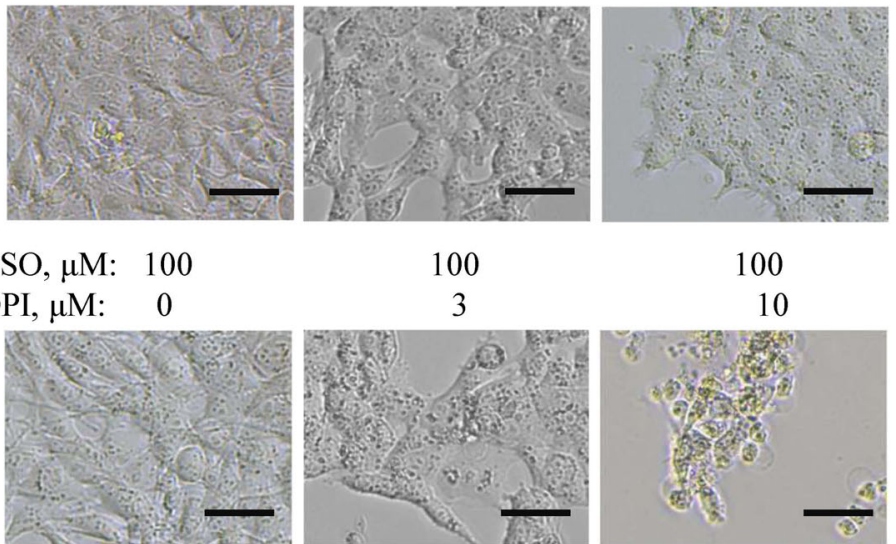

00

10
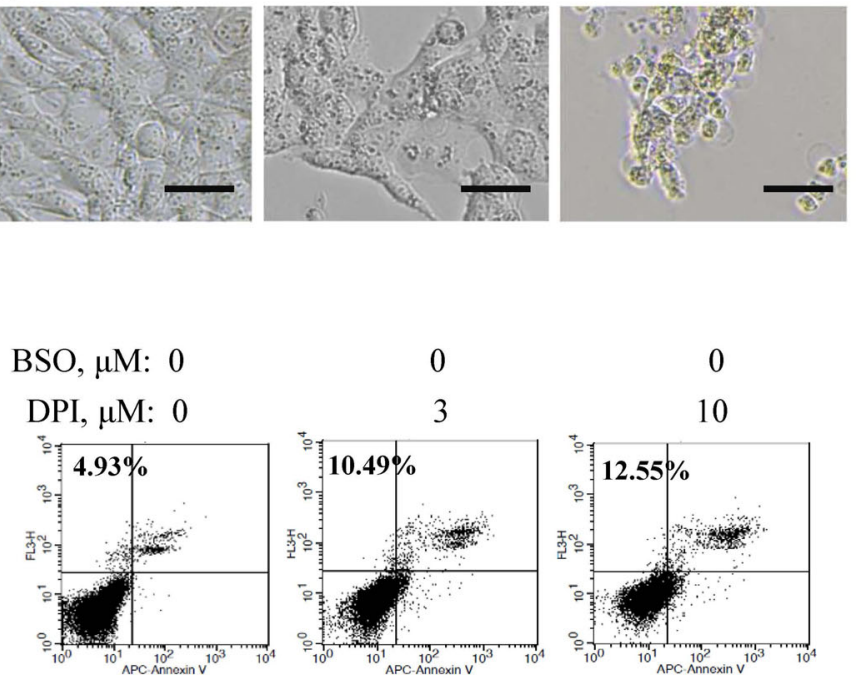

BSO, $\mu \mathrm{M}: 100$

DPI, $\mu \mathrm{M}: \quad 0$

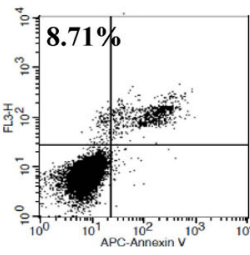

100

100

3

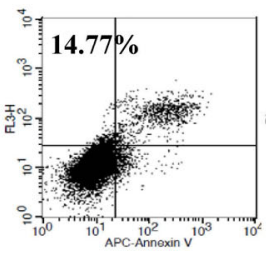

10

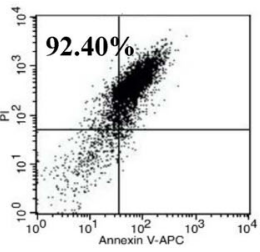

F

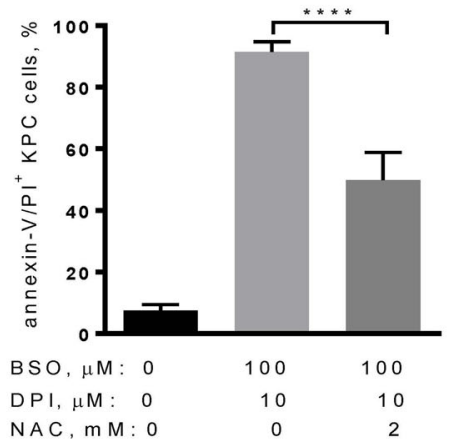

Fig. 5 (See legend on next page.) 
(see figure on previous page)

Fig. 5 Cytotoxicity of BSO and DPI combinatory treatment in murine KPC cells. A qRT-PCR analysis of pancreatic CYBA gene expression. At 60 days of age, randomly recruited male and female fElas ${ }^{\text {CreERT }}(n=4), \operatorname{KRAS}^{G 12 D /+}(n=3)$, and KPC mice $(n=6)$ were treated with TM. Three weeks post TM induction, the pancreata were collected for RNA extraction. $\beta$-actin serves as a control. B An equal number of KPC cancer cells were seeded in 6-well plates and treated with DPI at 0,3, or $10 \mu \mathrm{M}$ in the presence or absence of $100 \mu \mathrm{M}$ BSO for $48 \mathrm{~h}$. Cell morphology, population growth, and death were observed under a light microscope. KPC cells without any treatment served as the control. Scale bar, $200 \mu$ m. C Total cellular glutathione (GSX) was measured after $24 \mathrm{~h}$ of BSO treatment at 0, 100, or $200 \mu \mathrm{M}$ in KPC cells by spectrophotometry. D KPC cancer cells were treated with 3 or $10 \mu \mathrm{M}$ DPI alone, $100 \mu \mathrm{M}$ BSO alone, or the combined DPI (1 or $3 \mu \mathrm{M})$ and BSO $(100 \mu \mathrm{M})$ for $48 \mathrm{~h}$. Cell death rates were probed by annexin-V/PI assay. KPC cells without any treatment served as the control. E KPC cells were treated with $10 \mu \mathrm{M} \mathrm{DPI}$ and $100 \mu \mathrm{M} \mathrm{BSO}$ in the presence or absence of $2 \mathrm{mM}$ NAC for $48 \mathrm{~h}$ to assess the changes in cell death rates by flow cytometry using the annexin-V/PI assay. F Statistical analysis of KPC cell death rates in E. Data are mean \pm SD of three independent experiments with Student's $t$ test. ${ }^{*} p<0.05,{ }^{* *} p<0.01,{ }^{* * *} p<0.001,{ }^{* * *} p<0.0001$.
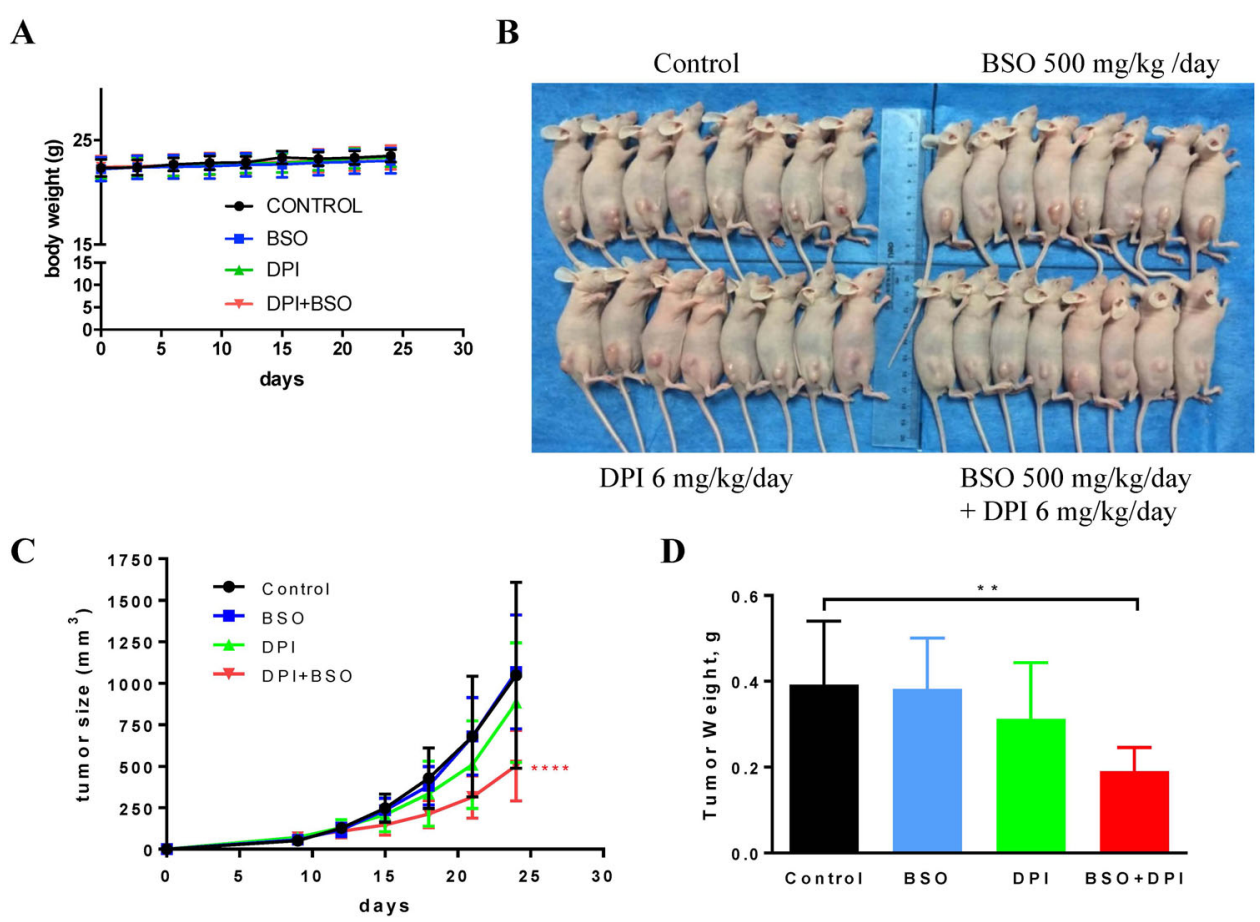

$\mathbf{D}$

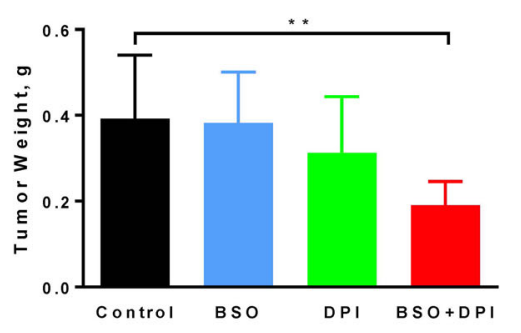

Fig. 6 Inhibition of pancreatic tumor growth in vivo by BSO and DPI combinatory treatment. A-D Athymic nude mice $(n=32)$ were injected subcutaneously with $5 \times 10^{5} \mathrm{KPC}$ cells on the right flank at the age of 9 weeks and randomly divided into four groups $(n=8$ per group). Treatment started 9 days after KPC cell injection with PBS, $500 \mathrm{mg} / \mathrm{kg} \mathrm{BSO}, 6 \mathrm{mg} / \mathrm{kg}$ DPI, or $500 \mathrm{mg} / \mathrm{kg} \mathrm{BSO}$ plus $6 \mathrm{mg} / \mathrm{kg}$ DPI. When the tumor diameter reached $18 \mathrm{~mm}$ in a few mice, all mice were sacrificed as mandated by the animal care protocol, and tumor nodules were excised for subsequent statistic comparison in size and weight. A Body weight changes in all 32 mice starting from KPC cell injection. No difference was noted in all four treatment groups. Two-way ANOVA was used for statistical analysis. B Photographic gross comparison of athymic nude mice bearing KPC cell xenografts on the right flank. C Tumor volumes were measured throughout the experiment to evaluate the effect of drug treatment using the following equation: tumor volume $\left(\mathrm{mm}^{3}\right)=L \times W \times(L+W) / 2 \times 0.526$. Data presented are mean tumor volume in $\mathrm{mm}^{3} \pm S D$. Two-way ANOVA was used for statistical analysis. ${ }^{* * *} p<0.0001$. D Statistic analysis of tumor weight among four treatment groups. Data presented are mean tumor weight \pm SD (gram). Student's $t$ test. ${ }^{* *} p<0.01$.

Overall, our results have shown that the acquired dual elevations in NOX activity and glutathione pool create a therapeutic vulnerability in oncogenic RAStransformed cancer cells. Targeting such a unique vulnerability by concurrently inhibiting NOX and glutathione synthesis induces a cooperative lethality highly potent to cancer cells harboring oncogenic RAS. Thus, our results not only have potentially important mechanistic implications in how both the oxidative and antioxidant arms of redox homeostasis cooperate to regulate cell survival and death, but also provide a promising therapeutic strategy for cancer patients harboring oncogenic RAS that warrants further translational and clinical investigation. 


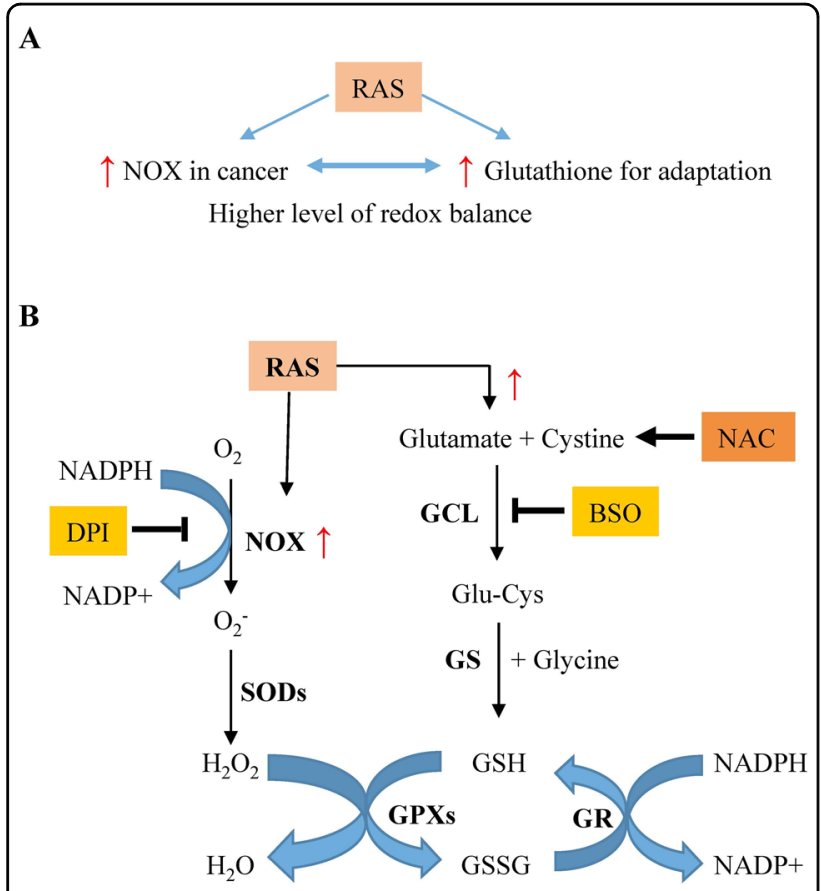

Fig. 7 Targeted inhibition of NOX activation and glutathione biosynthesis for treating mutant RAS-harboring cancers. A Oncogenic RAS activation enhances both ROS-generating NOX and ROS-scavenging glutathione biosynthesis to induce a higher level of redox balance for optimal survival and proliferation of cancer cells. B NOX catalyzes the oxidation of NADPH to $\mathrm{NADP}^{+}$, leading to the generation of $\mathrm{O}_{2}{ }^{-}$by the reduction of molecule oxygen $\left(\mathrm{O}_{2}\right) \cdot \mathrm{O}_{2}{ }^{-}$can be converted to other forms of reactive oxygen species (ROS), the levels of which can be regulated by the reduced glutathione and glutathione-coupled antioxidant enzymes. Normal cells keep the ROS and antioxidant capacity at basal levels. However, oncogenic RAS activates NOX activity, leading to an increase in ROS generation. It also upregulates $\mathrm{GCL}$ and other enzymes in glutathione biosynthesis, leading to an elevated cellular glutathione pool. As a result, the heightened oxidative stress and antioxidant capability, at a certain threshold with an adequate range, achieve a higher level of redox balance, on which cancer cells depend to gain a selective advantage on survival and proliferation in adverse conditions. On the other hand, the coexistence of both elevated redox arms irrevocably creates a vulnerability and, thus, an opportunity for the targeted therapy, as exemplified by the combined DPI and BSO treatment in this study. Exogenous NAC can, directly and indirectly, replenish the reduced cellular glutathione pool to significantly attenuate the cytotoxic effects of the combination therapy.

\section{Acknowledgements}

We thank Drs. Peng Huang and Jinsong Liu for providing several cancer cell lines, such as $\mathrm{HCT}_{116^{+/+}}$cells, HCT116 ${ }^{-/-}$cells, T72 cells, and T72Ras cells.

\section{Author details}

'Department of Gastroenterology, Changhai Hospital, Shanghai, China. ${ }^{2}$ Department of Gastroenterology, No. 905 Hospital, Shanghai, China. ${ }^{3}$ Division of Gastroenterology and Hepatology, Department of Medicine, Stony Brook University, Stony Brook, NY, USA. ${ }^{4}$ School of Pharmaceutical Sciences \& The First Affiliated Hospital of Wenzhou Medical University, Wenzhou, Zhejiang, China. ${ }^{5}$ Division of Medical Oncology, Department of Medicine, Duke Cancer Institute, Duke University, Durham, NC, USA

\section{Author contributions}

Conception and design: W.L. Study supervision: Z.L. and W.L. Acquisition of data: M.L., D.W., Y. L., Y.B., J.J., G.W., L.Z., J.M., C.K.L., E.K., and W.L. Analysis and interpretation of data: M.L., D.W., Y.L., L.H., Y.B., J.J., H.H., G.W., L.Z., J.M., E.K., C.K.L., J.L.A., X.L., V.W.Y., Z.L., and W.L. Drafting of the manuscript: W.L., M.L., D.W., Y.L., C.K.L., J.L.A., and V.W.Y. Revising critically for important intellectual content: M.L., D.W., Y.L., L.H., Y.B., J.J., H.H., G.W., L.Z., J.M., E.K., C.K.L., J.L.A., X.L., V.W.Y., Z.L., and W.L. Final approval of the version to be published: M.L., D.W., Y.L., L.H., Y.B., J.J., H.H., G.W., L.Z., J.M., E.K., C.K.L., J.L.A., X.L., V.W.Y., Z.L., and W.L.

\section{Ethics statement}

All procedures for generating and experimenting with the fElas ${ }^{\text {GreeRT }} ; K_{\text {Kas }}{ }^{\text {LSLGI2D/+ }}$

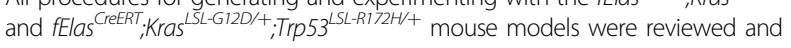
approved by the Stony Brook University Institutional Animal Care and Use Committee (IACUC). The generation and experimental use of KPC cell xenograft mouse models were reviewed and approved by the IACUC at Changhai Hospital.

\section{Funding}

This work was supported by 1R56DK123079-01, 1R01DK123079-01, and 1R01CA240818-01A1 from the NIH, W81XWH-20-1-0625 from the DoD, a Startup Fund and a SUNY Central Award from Stony Brook University, and a Pilot Project Grant from the Department of Medicine at Stony Brook University to W.L., as well as the National Natural Science Foundation of China (81270540 and 81670585 ) to Z.L.

\section{Conflict of interest}

The authors declare that they have no conflict of interest.

\section{Publisher's note}

Springer Nature remains neutral with regard to jurisdictional claims in published maps and institutional affiliations.

Received: 7 October 2020 Revised: 14 January 2021 Accepted: 19 January 2021

Published online: 16 February 2021

\section{References}

1. Varras, M. N. et al. Detection and clinical correlations of ras gene mutations in human ovarian tumors. Oncology 56, 89-96 (1999).

2. Cancer Genome Atlas Research N. Comprehensive molecular profiling of lung adenocarcinoma. Nature 511, 543-550 (2014).

3. Cancer Genome Atlas N. Comprehensive molecular characterization of human colon and rectal cancer. Nature 487, 330-337 (2012).

4. Hezel, A. F., Kimmelman, A. C., Stanger, B. Z., Bardeesy, N. \& Depinho, R. A. Genetics and biology of pancreatic ductal adenocarcinoma. Genes Dev. 20, 1218-1249 (2006).

5. Shah, Y. M. \& Lyssiotis, C. A. Mitochondrial amino acid metabolism provides vulnerabilities in mutant KRAS-driven cancers. Gastroenterology 151, 798-801 (2016).

6. Vander Heiden, M. G. Targeting cancer metabolism: a therapeutic window opens. Nat. Rev. Drug Discov. 10, 671-684 (2011).

7. Weinberg, F. et al. Mitochondrial metabolism and ROS generation are essential for Kras-mediated tumorigenicity. Proc. Natl Acad. Sci. USA 107, 8788-8793 (2010)

8. Wong, C. C. et al. SLC25A22 promotes proliferation and survival of colorectal cancer cells with KRAS mutations and xenograft tumor progression in mice via intracellular synthesis of aspartate. Gastroenterology 151, 945-60 e6 (2016).

9. Ying, H. et al. Oncogenic Kras maintains pancreatic tumors through regulation of anabolic glucose metabolism. Cell 149, 656-670 (2012).

10. Lu, W. et al. Novel role of NOX in supporting aerobic glycolysis in cancer cells with mitochondrial dysfunction and as a potential target for cancer therapy. PLoS Biol. 10, e1001326 (2012).

11. Irani, K. et al. Mitogenic signaling mediated by oxidants in Ras-transformed fibroblasts. Science 275, 1649-1652 (1997).

12. Trachootham, D. et al. Selective killing of oncogenically transformed cells through a ROS-mediated mechanism by beta-phenylethyl isothiocyanate. Cancer Cell 10, 241-252 (2006). 
13. Vaquero, E. C., Edderkaoui, M., Pandol, S. J., Gukovsky, I. \& Gukovskaya, A. S. Reactive oxygen species produced by $\mathrm{NAD}(\mathrm{P}) \mathrm{H}$ oxidase inhibit apoptosis in pancreatic cancer cells. J. Biol. Chem. 279, 34643-34654 (2004).

14. Bedard, K. \& Krause, K. H. The NOX family of ROS-generating NADPH oxidases: physiology and pathophysiology. Physiol. Rev. 87, 245-313 (2007).

15. Panday, A., Sahoo, M. K. Osorio, D. \& Batra, S. NADPH oxidases: an overview from structure to innate immunity-associated pathologies. Cell Mol. Immunol. 12, 5-23 (2015).

16. Trachootham, D., Alexandre, J. \& Huang, P. Targeting cancer cells by ROSmediated mechanisms: a radical therapeutic approach? Nat. Rev. Drug Discov. 8, 579-591 (2009).

17. Trachootham, D., Lu, W., Ogasawara, M. A., Nilsa, R. D. \& Huang, P. Redox regulation of cell survival. Antioxid. Redox Signal. 10, 1343-1374 (2008).

18. Lu, W., Ogasawara, M. A. \& Huang, P. Models of reactive oxygen species in cancer. Drug Discov. Today Dis. Models 4, 67-73 (2007).

19. Kerr, E. M., Gaude, E., Turrell, F. K., Frezza, C. \& Martins, C. P. Mutant Kras copy number defines metabolic reprogramming and therapeutic susceptibilities. Nature 531, 110-113 (2016).

20. DeNicola, G. M. et al. Oncogene-induced Nrf2 transcription promotes ROS detoxification and tumorigenesis. Nature 475, 106-109 (2011).

21. Hu, Y. et al. K-ras(G12V) transformation leads to mitochondrial dysfunction and a metabolic switch from oxidative phosphorylation to glycolysis. Cell Res. 22, 399-412 (2012).

22. Menegon, S., Columbano, A. \& Giordano, S. The dual roles of NRF2 in cancer. Trends Mol. Med. 22, 578-593 (2016).

23. Lau, A., Villeneuve, N. F., Sun, Z., Wong, P. K. \& Zhang, D. D. Dual roles of Nrf2 in cancer. Pharm. Res. 58, 262-270 (2008).

24. Rojo de la Vega, M., Chapman, E. \& Zhang, D. D. NRF2 and the hallmarks of cancer. Cancer Cell 34, 21-43 (2018).

25. Young, T. W. et al. Activation of antioxidant pathways in Ras-mediated oncogenic transformation of human surface ovarian epithelial cells revealed by functional proteomics and mass spectrometry. Cancer Res. 64, 4577-4584 (2004).
26. Chio, I. I. et al. NRF2 promotes tumor maintenance by modulating mRNA translation in pancreatic cancer. Cell 166, 963-976 (2016).

27. Griffith, O. W. Mechanism of action, metabolism, and toxicity of buthionine sulfoximine and its higher homologs, potent inhibitors of glutathione synthesis. J. Biol. Chem. 257, 13704-13712 (1982).

28. Altenhofer, S., Radermacher, K. A., Kleikers, P. W., Wingler, K. \& Schmidt, H. H. Evolution of NADPH oxidase inhibitors: selectivity and mechanisms for target engagement. Antioxid. Redox Signal. 23, 406-427 (2015).

29. Hingorani, S. R. et al. Preinvasive and invasive ductal pancreatic cancer and its early detection in the mouse. Cancer Cell 4, 437-450 (2003).

30. Wang, D. et al. Obesogenic high-fat diet heightens aerobic glycolysis through hyperactivation of oncogenic KRAS. Cell Commun. Signal 17, 19 (2019).

31. Luo, Y. et al. Oncogenic KRAS reduces expression of FGF21 in acinar cells to promote pancreatic tumorigenesis in mice on a high-fat diet. Gastroenterology 157, 1413-28.e11 (2019).

32. Liu, J. et al. A genetically defined model for human ovarian cancer. Cancer Res. 64, 1655-1663 (2004).

33. Deer, E. L. et al. Phenotype and genotype of pancreatic cancer cell lines. Pancreas 39, 425-435 (2010).

34. Hingorani, S. R. et al. Trp53R172H and KrasG12D cooperate to promote chromosomal instability and widely metastatic pancreatic ductal adenocarcinoma in mice. Cancer Cell 7, 469-483 (2005).

35. Bruns, C. J., Harbison, M. T., Kuniyasu, H., Eue, I. \& Fidler, I. J. In vivo selection and characterization of metastatic variants from human pancreatic adenocarcinoma by using orthotopic implantation in nude mice. Neoplasia 1, 50-62 (1999).

36. Gysin, S., Rickert, P., Kastury, K. \& McMahon, M. Analysis of genomic DNA alterations and mRNA expression patterns in a panel of human pancreatic cancer cell lines. Genes Chromosom. Cancer 44, 37-51 (2005).

37. Bailey, J. M. et al. p53 mutations cooperate with oncogenic Kras to promote adenocarcinoma from pancreatic ductal cells. Oncogene 35, 4282-4288 (2016)

38. Jin, L. et al. Glutamate dehydrogenase 1 signals through antioxidant glutathione peroxidase 1 to regulate redox homeostasis and tumor growth. Cancer Cell 27, 257-270 (2015). 